\title{
Iglesia de los pobres. Del Vaticano II a Medellín y nuestros días ${ }^{*}$
}

\author{
Francisco de Aquino Júnior, \\ Facultad Católica de Fortaleza, \\ Brasil
}

En su mensaje al mundo, el 11 de septiembre de 1962, un mes antes de la apertura del Concilio Vaticano II, el papa Juan XXIII, hablando de la misión de la Iglesia en el mundo de hoy, presentó de forma sorprendente e inesperada lo que calificó como un "punto luminoso". "Pensando en los países subdesarrollados, la Iglesia se presenta y quiere realmente ser la Iglesia de todos, en particular, la Iglesia de los pobres"'. Y así, apareció ante el concilio el tema de la Iglesia de los pobres.

La verdad es que en el concilio, el tema tuvo una acogida y una repercusión muy tímida, y no podía ser de otra manera. A fin de cuentas, a pesar de todos sus grandes méritos y de su importancia, el Vaticano II fue fundamentalmente un concilio de las Iglesias del Primer Mundo, y su dirección fue la de esas Iglesias. Con todo, la indicación y provocación profética de Juan XXIII estuvo presente a lo largo de las sesiones conciliares, sobre todo a través del grupo de obispos conocido como "Iglesia de los pobres". Pero solo en la II Conferencia del Episcopado Latinoamericano en Medellín (1968) la provocación de Juan XXIII encontró tierra fértil. A partir de Medellín, la Iglesia en América Latina se convertirá cada vez más en la Iglesia de los pobres, sacramento universal de salvación.

$\mathrm{Al}$ celebrar los 50 años de ese mensaje "iluminador", que para alegría de unos y escándalo de otros indicó proféticamente el rumbo que la Iglesia debe tomar si quiere ser en realidad la Iglesia de Jesucristo, queremos recordar - traer de nuevo

* En este artículo mantenemos los títulos de libros y revistas tal como aparecen en el original portugués, con alguna excepción que el lector notará con facilidad.

1. Juan XXIII, "Mensagem radiofônica a todos os fiéis católicos, a um mês da abertura do Concílio", en Vaticano II, Mensages discursos e documentos, São Paulo, Paulinas, 2007, 20-26, letra L. 
al corazón de la fe y de la Iglesia- su importancia y su impacto en el concilio y en la Iglesia latinoamericana, así como su actualidad y relevancia históricoteologal. Para eso, comenzaremos analizando la acogida y repercusión del tema en el concilio (1), así como en la Conferencia de Medellín (2). Y concluiremos analizando su actualidad y relevancia histórico-teologal (3).

\section{1. "Iglesia de los pobres" en el Vaticano II}

En la Constitución Apostólica de la convocatoria del concilio (25 de diciembre de 1961), el papa Juan XXIII considera que parte de su ministerio apostólico consiste en "dedicar todos los esfuerzos para que la Iglesia contribuya con el trabajo de sus hijos en la busca de soluciones idóneas para los grandes problemas humanos de nuestra época"2. Y desde esa perspectiva, justifica la convocatoria de un nuevo concilio.

Lo que está en juego es la juventud siempre irradiante de nuestra madre Iglesia, llamada a estar presente en todos los acontecimientos humanos y a renovarse constantemente con el pasar de los siglos, adquiriendo en cada época o circunstancia un nuevo brillo y enriqueciéndose con nuevos méritos, a pesar de permanecer siempre la misma, reflejando siempre la imagen de Jesucristo, que la ama y la protege como esposo. ${ }^{3}$

En su mensaje al mundo, el 11 de septiembre de 1962, habla del concilio "en vista a la aplicación más sabia y hoy posible del magisterio evangélico de Cristo, que desde hace veinte siglos ilumina la humanidad salvada por su sangre"4. Y en el discurso de apertura (11 de octubre de 1962), afirma que "el concilio debe cuidar, sobre todo, de conservar y proponer de manera más eficaz el depósito de la fe"

La Iglesia debe mantenerse fiel al patrimonio de la verdad recibida del pasado $\mathrm{y}$, al mismo tiempo, estar atenta al presente y a las nuevas formas de vida introducidas por la modernidad, que abren perspectivas inéditas al apostolado católico. ${ }^{6}$

La doctrina es siempre la misma, pero es preciso que sea más amplia y profundamente conocida [...]. La doctrina correcta es inmutable [...], debe pues ser investigada y expuesta por la razón de acuerdo con las exigencias de la

2. Juan XXIII, "Constituição Apostólica Humanae Salutis. Convocação do Concílio Ecumênico Vaticano II”, ibíd., 11-18, n. ${ }^{\circ} 6$.

3. Ibid., n. 7 .

4. Juan XXIII, "Mensagem radiofônica a todos os fiéis católicos, a um mês da abertura do Concílio", op. cit., n. ${ }^{\circ} 25^{\text {a }}$.

5. Juan XXIII, "Discurso do papa João XXIII Gaudet Mater Ecclesia na abertura solene do Concílio", en Vaticano II, Mensages discursos e documentos, op. cit., $27-35, n .^{\circ} 45$.

6. Ibid., n. 49 . 
actualidad. Una cosa es el depósito de la fe [...], otra el modo como [las verdades de la fe] son expresadas.?

Finalmente, en el mensaje enviado a la humanidad por los padres conciliares en comunión con el papa, el 20 de octubre de 1962, una semana después del inicio de los trabajos, afirma:

Bajo la inspiración (modo de proceder) del Espíritu Santo queremos descubrir en esta reunión qué debemos hacer para renovarnos, tornándonos cada día más fieles al Evangelio de Cristo, buscando cómo comunicar la verdad de Dios, íntegra y pura, para que los seres humanos de hoy la entiendan y la acojan en libertad. ${ }^{8}$

No es casualidad que se refieran a los problemas y desafíos centrales del concilio en términos de aggiornamento: actualización, renovación, rejuvenecimiento. Y aggionarmento en referencia a los signos de los tiempos 9 . Dos expresiones fundamentales para entender el concilio, tal como fue pensado y propuesto por Juan XXIII.

A partir de y en vista de esa intuición fundamental (aggiornamento-signo de los tiempos), se pueden comprender mejor los tres grandes temas propuestos al concilio por el papa: apertura al mundo moderno, unidad de los cristianos e Iglesia de los pobres ${ }^{10}$. Ciertamente, los dos primeros encontraron gran acogida entre los padres conciliares y determinaron el rumbo del concilio, lo que respondía mejor a los intereses de las Iglesias del Primer Mundo. El tema de la "Iglesia de los pobres", aunque de forma marginal y secundaria, se haría presente a lo largo de todo el evento conciliar como un clamor que irrumpía desde los países pobres y del mundo obrero de los países ricos, que provocaba y desafiaba proféticamente a la Iglesia.

Como indicamos antes, el tema aparece por primera vez en el mensaje enviado al mundo por el papa Juan XXIII el 11 de septiembre de 1962, exactamente un mes antes de la apertura del concilio. Es interesante que el tema no figure en los primeros textos del papa sobre el concilio, y en ese mensaje irrumpa de forma sorprendente e inesperada ${ }^{11}$. Hablando de Cristo como luz y de la misión de la Iglesia en el mundo, el papa recuerda los "graves problemas" con los que se enfrenta el mundo, la preocupación y responsabilidad de la Iglesia

7. Ibid., n. ${ }^{\circ} 55$.

8. "Mensagem enviada à humanidade pelos membros do Concílio Ecumênico Vaticano II, com o assentimento do soberano Pontífice", ibid., 35-38, n. 72.

9. Cf. C. Boff, "Sinais dos Tempos": Princípios de leitura, São Paulo: Loyola, 1979.

10. $C f$. G. Gutiérrez, "O Concílio Vaticano II na América Latina”, en J. Ó. Beozzo, (coord.), O Vaticano II e a Igreja Latino-americana, São Paulo: Paulinas, 1985, pp. 17-49, aquí p. 23.

11. Cf. ibid., pp. 27 y s. 
por esos problemas y la contribución que el concilio podrá dar a la solución de los mismos "basada en la dignidad del ser humano y en su vocación cristiana". Para ello, señala algunos puntos importantes: la igualdad de todos los pueblos en el ejercicio de los derechos y los deberes, la defensa del matrimonio y la responsabilidad social. En ese contexto, añade lo que califica como "otro punto iluminador": "Pensando en los países subdesarrollados, la Iglesia se presenta y quiere ser realmente la Iglesia de todos, en particular, la Iglesia de los pobres"12.

Comentando ese texto, Gustavo Gutiérrez destaca tres aspectos fundamentales. En primer lugar, "el papa sitúa a la Iglesia en relación con los países pobres", que ya no serán tratados como países "en vías de desarrollo", como en Mater et magistra, sino como "países subdesarrollados"13. El misterio de la Iglesia (liberación en Cristo, proximidad del Reino de Dios) es pensado en su relación esencial con los pobres. En segundo lugar, "establece los términos de una relación importante" entre "Iglesia de todos" (universalidad de la misión) e "Iglesia de los pobres" (particularidad, predilección). "Esta dialéctica entre universalidad y particularidad es crucial para comprender el mensaje cristiano que Dios revela en él" ${ }^{14}$. Por último, "Juan XXIII presenta esta visión de la Iglesia como una realidad en proceso": lo que la Iglesia "es y quiere ser". En otras palabras, "no todo está hecho. La Iglesia aún no es todo lo que debería ser, hay un trayecto histórico que se debe emprender"15. Como afirma Gutiérrez, "se trata de un texto breve, en el que sin embargo cada palabra es importante. Su sobriedad y modestia no deben hacernos olvidar su carácter de fuente"16.

De hecho, el texto se convirtió en "fuente de un movimiento de extrema importancia en el proceso de renovación conciliar de la Iglesia: su relación esencial con los pobres de este mundo". Este movimiento fue dinamizado y articulado por un grupo de padres conciliares que se conoció con el nombre de "Iglesia de los pobres"17. Provocados e inspirados por la experiencia del padre

12. Juan XXIII, "Mensagem radiofônica a todos os fiéis católicos, a um mês da abertura do Concílio" op. cit., letra L.

13. G. Gutiérrez, "O Concílio Vaticano II na América Latina”, op. cit., p. 29.

14. Ibid., p. 30.

15. Ibidem.

16. Ibidem.

17. Cf. G. Alberigo, Breve história do Concílio Vaticano II, Aparecida: Santuário, 2006, pp. 39 y s., 56 y s., 62, 132 y s., 191 y s.; J. Ó. Beozzo, "Presença e atuação dos bispos brasileiros no Vaticano II", en P. S. Lopes Gonçalves y V. I. Bombonatto (coords.), Concílio Vaticano II: análise e prospectivas, São Paulo: Paulinas, 2004, pp. 117-162, aquí pp. 147-150; M. D. Chenu, "A Igreja e os pobres no Vaticano II”, Concílium 124 (1977), pp. 61-66; G. Gutiérrez, "O Concílio Vaticano II na América Latina”, op. cit., pp. 31-33; Á. Barreiro, Os pobres e o Reino: Do Evangelho a João Paulo II, São Paulo: Loyola, 1983, pp. 135-138; J. M. Vigil, Vivendo o Concílio. Guia para a animação conciliar da comunidade cristã, São Paulo: Paulinas, 1987, pp. 164-170. 
Paul Gauthier y de la religiosa carmelita Marie-Thérèse Lescase, junto a los obreros de Nazaret, así como por el libro Los pobres, Jesús y la Iglesia, de Paul Gauthier $^{18}$, varios obispos y teólogos comenzaron a reunirse regularmente en el Colegio Belga de Roma bajo la presidencia del cardenal francés Gerlier, en torno al proyecto de la "Iglesia de los pobres". El grupo se convirtió en un lugar privilegiado de sensibilización y reflexión teológica sobre la relación entre Jesús, la Iglesia y los pobres, y fue fuente de inspiración de muchas intervenciones en las salas conciliares ${ }^{19}$. Entre ellas, merece destacarse la famosa intervención del cardenal Lercaro, de Bolonia, al final de la primera sesión del concilio.

Uno de los aspectos más destacados de la primera sesión y, sin duda, determinante para todo el concilio, fue la discusión en los últimos días de esa sesión del proyecto sobre la Iglesia. Fue entonces cuando se definió más claramente el rumbo del concilio. En ese proceso fue decisiva la intervención del cardenal belga Suenens el 4 de diciembre $1962^{20}$.

Antes de concluir esta primera sesión, me gustaría proponer a los padres conciliares para su cuidadosa consideración cuál sería el objetivo principal de este consejo [...]. Es importante que nos pongamos de acuerdo sobre el desarrollo de un plan conjunto para el propio concilio [...]. Este plan propondría lo siguiente: que el concilio sea el concilio sobre la Iglesia y tenga dos partes: de Ecclesia ad intra-de Ecclesia ad extra. ${ }^{21}$

La propuesta de Suenens fue muy bien acogida por los padres conciliares, especialmente por el cardenal Montini, entonces arzobispo de Milán. "¿Qué es la Iglesia? ¿Qué hace la Iglesia? Estos son los dos ejes en torno a los cuales deben girar todos los temas del concilio. El misterio de la Iglesia es la misión que le fue confiada y que ella tiene que realizar, el tema alrededor del cual debe girar el concilio"22.

18. Cf. P. Gauthier, Les pauvres, Jesus et l'Eglise, París: Éditions Universitaires, 1962. El padre Paul Gauthier era profesor de teología dogmática en el seminario mayor de Dijon, Francia. En 1955 dejó la cátedra y fue a vivir y a trabajar como obrero en Nazaret. Durante el concilio, fue a Roma y desempeñó un papel fundamental de reflexión y articulación junto a un grupo de obispos y teólogos sobre la relación entre Jesús e Iglesia de los pobres.

19. Para una visión de conjunto de las intervenciones de los padres en las aulas conciliares sobre esta cuestión, $c f$. P. Gauthier, $O$ Concílio e a Igreja dos pobres: "Consolai meu povo", Petrópolis: Vozes, 1967; y O Evangelho da justiça, Petrópolis: Vozes, 1969.

20. Cf. G. Alberigo, Breve história do Concílio Vaticano II, op. cit., pp. 60 y ss.; I. Camacho, Doutrina Social da Igreja: abordagem histórica, São Paulo: Loyola, 1995, pp. 250 y ss.

21. Leo Joseph Suenens, en I. Camacho, op. cit., p. 251.

22. Giovanni Battista Montini, ibidem. 
En este contexto, se inserta la intervención del cardenal Lercaro el 6 de diciembre de 1962, a la que nos referíamos antes. Comienza reforzando la tesis de Suenens y de Montini: la "finalidad de este concilio" debe ser una "doctrina sobre la Iglesia capaz de ir hasta los fundamentos más allá de los rasgos de orden jurídico". Constata una laguna en los esquemas presentados a la apreciación de los padres: no consideran "el misterio de Cristo en los pobres", y esta es una verdad "esencial y primordial" en la revelación. Por ello,

al concluir esta primera sesión de nuestro concilio, es importante reconocer y proclamar solemnemente: no realizaremos nuestra tarea en manera suficiente, no recibiremos con un espíritu abierto el proyecto de Dios y la expectativa de los hombres, si no colocamos, como centro y alma del trabajo doctrinal y legislativo de este concilio, el misterio de Cristo en los pobres y la evangelización de los pobres.

Y continúa:

No satisfaremos la más profunda y verdadera exigencia de nuestro tiempo [...], sino que huiremos de ella, si tratamos el tema de la evangelización de los pobres como uno de los numerosos temas del concilio. Si en verdad la Iglesia, como ya se ha dicho muchas veces, es el tema de este concilio, se puede afirmar, en plena conformidad con la eterna verdad del Evangelio, y al mismo tiempo en perfecto acuerdo con la coyuntura presente, que el tema de este concilio es realmente la Iglesia en cuanto es sobre todo "la Iglesia de los pobres".

Propone algunos asuntos doctrinales para ser abordados y desarrollados, y algunas reformas pastorales e institucionales. Y concluye mencionando el "primado de la evangelización de los pobres" como "método auténtico" de anuncio del Evangelio, de restauración de la unidad de los cristianos y de respuesta a los hombres de nuestro tiempo ${ }^{23}$.

El grupo "Iglesia de los pobres", aunque sobre muchos padres conciliares ejerció un influjo espiritual y profético significativo, quedó siempre al margen del concilio. Su repercusión en los documentos aprobados fue muy tímida ${ }^{24}$. Hay que reconocer, por lo tanto, que "el grupo no consiguió lo que esperaba institucionalmente del concilio" 25 , y que "estamos lejos de la propuesta del cardenal Lercaro, hacer de la cuestión de la 'Iglesia de los pobres' (expresión no retomada

23. Giacomo Lercaro, en P. Gauthier, $O$ Concílio e a Igreja dos pobres, op. cit., pp. 178-182.

24. Cf. J. M. Vigil, Vivendo o Concílio, op. cit.; G. Gutiérrez, "O Concílio Vaticano II na América Latina", op. cit., pp. 32 y s.

25. J. Ó. Beozzo, "Presença e atuação dos bispos brasileiros no Vaticano II", op. cit., p. 150. 
en el Vaticano II) el tema del concilio"26. En cualquier caso, sí recuperó y dio visibilidad a un aspecto "esencial y primordial" de la revelación y puso en marcha un proceso de renovación eclesial a partir de y en vista de su relación "esencial y primordial" con los pobres de este mundo, comenzando por el compromiso asumido por los propios miembros del grupo, en su vida y acción pastoral, en el Pacto de las Catacumbas, en la catacumba de Santa Domitila, en las afueras de Roma, el 16 de noviembre de $1965^{27}$ (ver anexo).

\section{2. "Iglesia de los pobres" en la Conferencia de Medellín}

Conscientes de que el sueño/proyecto de una "Iglesia de los pobres" no consiguió imponerse y determinar el rumbo del concilio, algunos obispos latinoamericanos se empeñaron en hacer que se convirtiera en "el tema eclesial principal" en América Latina ${ }^{28}$. Aquí hay que destacar especialmente la actuación de monseñor Manuel Larraín, obispo de Talca, Chile, y de monseñor Hélder Câmara, presidente y vicepresidente del CELAM, respectivamente ${ }^{29}$. Al final del concilio, ambos sintieron la necesidad y prepararon una reunión del episcopado latinoamericano "para ver nuestra situación a la luz del concilio"30. "Lo que vivimos fue impresionante, pero si en América Latina no estuviésemos atentos a nuestros propios signos de los tiempos, el concilio pasará al margen de nuestra Iglesia, y quién sabe lo que vendrá después", decía monseñor Manuel Larraín en Roma, en la última etapa del concilio ${ }^{31}$.

La Conferencia de Medellín (del 24 de agosto al 6 de septiembre de 1968 ${ }^{32}$ ) significó

26. G. Gutiérrez, "O Concílio Vaticano II na América Latina”, op. cit., p. 33.

27. Cf. B. Kloppenburg, Concílio Vaticano II, vol. V, Petrópolis: Vozes, 1966, pp. 526-528.

28. J. Ó. Beozzo, "Presença e atuação dos bispos brasileiros no Vaticano II", op. cit., p. 150.

29. $C f$. G. Gutiérrez, "O Concílio Vaticano II na América Latina", op. cit., p. 34; A. Lorscheider, Mantenham as Lâmpadas acesas: revisitando o Caminho, recriando a Caminhada, Fortaleza: UFC, 2008, pp. 74 y ss.

30. G. Gutiérrez, "O Concílio Vaticano II na América Latina”, op. cit., p. 34.

31. Ibid., p. 36.

32. Sobre la Conferencia de Medellín, cf. J. Ó. Beozzo, A Igreja do Brasil de João XXIII a João Paulo II: De Medellín a Santo Domingo, Petrópolis: Vozes, 1994; C. Caliman, "A trinta anos de Medellín: uma nova consciência eclesial na América Latina", Perspectiva Teológica 31 (1999), pp. 163-180; L. A. Gomes de Spusa, "A caminhada de Medellín a Puebla", Perspectiva Teológica 31 (1999), pp. 223-234; A. M. Tepedino, "De Medellín a Aparecida: marcos, trajetórias, perspectivas da Igreja Latino-americana”, Atualidade Teológica 36 (2010), pp. 376-394. 
la transposición de la perspectiva del concilio y de sus intuiciones al contexto específico del continente latinoamericano. Sin el concilio no habría existido Medellín, aunque Medellín no hubiera sido Medellín sin el esfuerzo audaz de repensar el acontecimiento conciliar a partir de la realidad de pobreza y de injusticia que caracterizaba a América Latina. ${ }^{33}$

Medellín no solo reconoció y desarrolló la riqueza y las potencialidades del concilio en América Latina, sino que, al hacerlo, puso en marcha un movimiento teológico-eclesial que acabó revelando límites del propio Vaticano II. Fue "un concilio universal, pero en la perspectiva de los países ricos y de la llamada cultura occidental" (Ellacuría) ${ }^{34}, \mathrm{y}$, por eso mismo, un concilio poco profético $\left(\right.$ Comblin) ${ }^{35}$, un concilio que acabó legándonos "una Iglesia de clase media" (Aloísio Lorscheider) ${ }^{36}$.

El concilio tuvo el mérito incalculable de descentrar la Iglesia y de abrirla y lanzarla al mundo, pero "no historizó debidamente lo que era ese mundo, el cual debía haber definido como un mundo de pecado, en el que las inmensas mayorías de la humanidad padecen de miseria e injusticia" ${ }^{37}$. No bastaba abrirse al mundo. Era necesario determinar con mayor claridad y precisión qué mundo era ese (estructuralmente injusto y opresor) y cuál era el lugar social de la Iglesia en él (mundo de los pobres y oprimidos). Aquí reside, paradójicamente, la gran limitación del concilio y el gran mérito de Medellín, tanto desde el punto de vista histórico (la situación concreta de nuestro mundo), como desde el punto de vista teologal/teológico (centralidad de los pobres en la historia de la salvación).

Redescubrir ese dato "esencial y primordial" de la revelación y de la fe cristiana permitió y ayudó a la Iglesia de América Latina a comprender mejor y más profundamente la realidad del continente y a redefinir, a partir de ahí, su acción pastoral. Es lo que se puede constatar ya en la introducción del documento final de la conferencia:

33. C. Palácio, "Trinta anos de teologia na América Latina: um depoimento", en L. C. Susin, (coord.), O mar se abriu: trinta anos de teologia na América Latina, São Paulo: Loyola, 2000, pp. 51-64, aquí p. 53.

34. I. Ellacuría, "Pobres", en Escritos teológicos, t. II, San Salvador: UCA Editores, 2000, pp. 171-192, aquí p. 173.

35. J. Comblin, A profecia na igreja, São Paulo: Paulus, 2009, pp. 185 y s.

36. A. Lorscheider, Mantenham as Lâmpadas acesas, op. cit., p. 142. En otra ocasión, distinguiendo la eclesiología del Vaticano II de la eclesiología latinoamericana, afirma: "El Vaticano II ignoró el submundo, el mundo de la injusticia institucionalizada, el mundo en el que ricos cada vez más ricos producen pobres cada vez más pobres a costa de esos mismos pobres" (En A. Lorscheider, "A Igreja no Ceará: desafios e perspectivas”, Kairós 1-2 [2004], pp. 64-70, aquí p. 69).

37. I. Ellacuría, "El auténtico lugar social de la Iglesia", en Escritos teológicos, t. II, op. cit., pp. 439-451, aquí p. 449. 
La Iglesia latinoamericana, reunida en la II Conferencia General de su Episcopado, centró su atención en el hombre de este continente, que vive un momento decisivo de su proceso histórico [...]. América Latina está evidentemente bajo el signo de transformación y el desarrollo [...].

Esto indica que estamos en el umbral de una nueva época histórica de nuestro continente, llena de un anhelo de emancipación total, de liberación de toda servidumbre, de madurez personal y de integración colectiva. Percibimos aquí los prenuncios en la dolorosa gestación de una nueva civilización. No podemos dejar de interpretar este gigantesco esfuerzo por una rápida transformación y desarrollo como un evidente signo del Espíritu que conduce la historia de los hombres y de los pueblos hacia su vocación [...].

Así como otrora Israel, el primer Pueblo, experimentaba la presencia salvífica de Dios cuando lo liberaba de la opresión de Egipto, cuando lo hacía pasar el mar y lo conducía hacia la tierra de la promesa, así también nosotros, nuevo Pueblo de Dios, no podemos dejar de sentir su paso que salva, cuando se da el "verdadero desarrollo", que es [...] el paso de condiciones de vida menos humanas [carencias morales y materiales, estructuras opresoras] a condiciones más humanas [poseer lo necesario, victoria sobre las calamidades sociales, ampliación de los conocimientos, cultura, dignidad humana, espíritu de pobreza, bien común, paz, valores, Dios, fe]..$^{38}$

Estas intuiciones fundamentales marcaron de modo radical las discusiones y el rumbo de la conferencia - toda ella centrada en la "búsqueda de una nueva y más intensa presencia de la Iglesia en la actual transformación de América Latina" ${ }^{39}$-, como se puede comprobar en sus 16 documentos (justicia, paz, familia y demografía, educación, juventud, pastoral de masas, pastoral de élites, catequesis, liturgia, movimientos laicos, sacerdotes, religiosos, formación del clero, pobreza de la Iglesia, colegialidad, medios de comunicación social). Todos estos temas están pensados y desarrollados, aunque de forma e intensidad diferentes, a partir del gran "signo de los tiempos" en América Latina: el deseo y el esfuerzo de "pasar del conjunto de condiciones inhumanas a la totalidad de condiciones plenamente humanas", y de "integrar toda la escala de valores temporales en la visión global de la fe cristiana" ${ }^{\prime 40}$.

Aquí conviene examinar con mayor atención el documento 14 que tiene como tema la "pobreza de la Iglesia" ${ }^{41}$. Como el resto de los documentos, está desarrollado según el conocido método ver-juzgar-actuar. Comienza tratando de

38. Consejo Episcopal Latinoamericano (CELAM), Conclusões de Medellín. II Conferência Geral do Episcopado Latino-america, São Paulo: Paulinas, 1987, pp. 5-7.

39. Ibid., p. 8.

40. Ibidem.

41. Cf. ibid., pp. 143-150. 
la "realidad latinoamericana", prosigue explicitando la "motivación doctrinal" y concluye con algunas "orientaciones pastorales".

Respecto a la "realidad latinoamericana", el texto comienza afirmando que el episcopado "no puede quedar indiferente ante las tremendas injusticias sociales existentes en América Latina, que mantienen a la mayoría de nuestros pueblos en una dolorosa pobreza cercana en muchísimos casos a la inhumana miseria". Habla del "sordo clamor" que "brota de millones de hombres, pidiendo a sus pastores una liberación que no les llega de ninguna parte", así como de las "quejas de que la Jerarquía, el clero, los religiosos, son ricos y aliados de los ricos". Hace algunas ponderaciones sobre la imagen que se tiene de la Iglesia. Llama la atención sobre la situación de pobreza de parroquias, diócesis, obispos, sacerdotes y religiosos. Distingue entre lo "necesario para la vida y cierta seguridad" y el carecer de lo "indispensable" para vivir. Concluye reconociendo que "no faltan casos en que los pobres sienten que sus obispos, o sus párrocos y religiosos, no se identifican realmente con ellos, con sus problemas y angustias, que no siempre apoyan a los que trabajan con ellos o abogan por su suerte" ${ }^{\text {"42 }}$.

En cuanto a la "motivación doctrinal", el documento distingue entre "pobreza como carencia", que es "un mal en sî́"; "pobreza espiritual", "actitud de apertura a Dios", "disponibilidad de quien todo espera del Señor"; y "pobreza como compromiso", asumida "por amor" a los pobres, a ejemplo de Cristo. A partir de estos tres significados de la pobreza, explica en qué consiste la pobreza de la Iglesia. Una Iglesia pobre, dice el texto, "denuncia la carencia injusta de los bienes de este mundo y el pecado que la engendra", "predica y vive la pobreza espiritual como actitud de infancia espiritual y apertura al Señor", y "se compromete ella misma con la pobreza material". Esto se aplica a "todos los miembros de la Iglesia", aunque se experimenta de maneras diferentes. Y vale de modo particular para el continente latinoamericano.

La Iglesia de América Latina, dadas las condiciones de pobreza y de subdesarrollo del continente, experimenta la urgencia de traducir ese espíritu de pobreza en gestos, actitudes y normas que la hagan un signo más lúcido y auténtico de su Señor. La pobreza de tantos hermanos clama justicia, solidaridad, testimonio, compromiso, esfuerzo y superación para el cumplimiento pleno de la misión salvífica encomendada por Cristo. ${ }^{43}$

Finalmente, y como consecuencia de lo dicho anteriormente, surge la gran orientación pastoral: "Queremos que la Iglesia de América Latina sea evangelizadora de los pobres y solidaria con ellos, testigo del valor de los bienes del Reino y humilde servidora de todos los hombres de nuestros pueblos" ${ }^{\prime 4}$. Y analiza tres

42. Ibid., pp. 143 y s.

43. Ibid., pp. 145 y s.

44. Ibid., p. 146. 
aspectos inseparables y al mismo tiempo irreductibles: "Preferencia y responsabilidad", "testimonio" y "servicio".

\section{a. Preferencia y solidaridad}

El particular mandato del Señor de evangelizar a los pobres debe llevarnos a una distribución de los esfuerzos y del personal apostólico que dé preferencia efectiva a los sectores más pobres y necesitados y a los segregados por cualquier causa [...]. Debemos agudizar la conciencia del deber de solidaridad con los pobres, a que la caridad nos lleva. Esta solidaridad significa hacer nuestros sus problemas y sus luchas, saber hablar por ellos. Esto ha de concretarse en la denuncia de la injusticia y la opresión, en la lucha cristiana contra la intolerable situación que soporta con frecuencia el pobre, en la disposición al diálogo con los grupos responsables de esa situación para hacerles comprender sus obligaciones [...]. La promoción humana ha de ser la línea de nuestra acción en favor del pobre [...]. Con ese fin reconocemos la necesidad de la estructuración racional de nuestra pastoral y de la integración de nuestros esfuerzos con los esfuerzos de otras entidades. ${ }^{45}$

\section{b. Testimonio}

Deseamos que nuestra habitación y estilo de vida sean modestos; nuestro modo de vestir, sencillo; nuestras obras e instituciones funcionales, sin aparato ni ostentación. Pedimos [...] un tratamiento que convenga a nuestra misión [...], pues deseamos renunciar a títulos honoríficos propios de otra época [...], esperamos superar el sistema arancelario [...]. La administración de los bienes diocesanos o parroquiales ha de estar integrada por laicos competentes y dirigida al mejor uso en bien de la comunidad toda.

En el mismo espíritu, exhorta a los "sacerdotes y a las comunidades religiosas", estimulando de modo particular a los que "se sienten llamados a compartir la suerte de los pobres" - insertándose y viviendo en medio de ellos - . "Estos ejemplos auténticos de desprendimiento y libertad de espíritu harán que los demás miembros del pueblo de Dios den testimonio análogo de pobreza"46.

\section{c. Servicio}

No impulsa a la Iglesia ambición terrena alguna, sino que quiere ser humilde servidora de todos los hombres. Necesitamos acentuar ese espíritu en nuestra América Latina. Queremos que nuestra Iglesia latinoamericana esté libre de ataduras temporales, de connivencias y de prestigio ambiguo; que "libre de

45. Ibid., pp. 146 y s.

46. Ibid., pp. 147 y ss. 
espíritu respecto a los vínculos de la riqueza", sea más transparente y fuerte su misión de servicio; presente en la vida y las tareas temporales, reflejando la luz de Cristo, presente en la construcción del mundo. ${ }^{47}$

Todo esto es lo que está a la base de lo que después se formuló y se consolidó como opción preferencial por los pobres - "la marca registrada del camino eclesial en América Latina" tológica/teológica. "La pobreza de tantos hermanos clama por justicia, esfuerzo y superación para el cumplimiento pleno de la misión salvífica confiada por Cristo" $"$. Por eso, Gustavo Gutiérrez insiste en que "la relevancia del pobre para el Reino de Dios y, por eso mismo, para el anuncio del Evangelio, es el nervio del cambio que experimenta la Iglesia latinoamericana". "Esta óptica llevó a la comunidad cristiana latinoamericana a retomar la intuición de Juan XXIII sobre la Iglesia de los pobres y a leer a partir de ahí los grandes temas conciliares para examinar su alcance para nuestro continente" ${ }^{50}$.

Este es el gran mérito y la gran contribución de Medellín a la Iglesia latinoamericana, y, por qué no decirlo, a toda la Iglesia: asumir de modo consecuente, tanto desde el punto de vista teológico como desde el eclesial/pastoral, ese aspecto "esencial y primordial" de la revelación cristiana que es la centralidad de los pobres y oprimidos en la historia de la salvación. Y aquí precisamente reside su insuperabilidad y perenne actualidad: poner en el centro de la vida y de la misión de la Iglesia aquello que está en el centro de la vida y la misión de Jesucristo, por más escandaloso que sea ( $c f$. Lc 7, 22s).

No es casual que se haya hablado de Medellín como "evento fundacional", "nuevo Pentecostés", "verdadero Kairós" de la Iglesia en América Latina ${ }^{51}$. En verdad, fue un acontecimiento que marcó de modo decisivo y radical el camino y el rostro de la Iglesia latinoamericana. Y no por casualidad monseñor Aloísio Lorscheider llega a afirmar que "ninguna conferencia, ni Puebla, y mucho menos Santo Domingo, sobrepasó a Medellín, que fue gran acontecimiento eclesial de América Latina, y marcó también a la Iglesia fuera de este continente. Influyó hasta en el magisterio general de la Iglesia" ${ }^{52}$.

47. Ibid., pp. 149 y s.

48. J. Ó. Beozzo, "Presença e atuação dos bispos brasileiros no Vaticano II", op. cit., p. 150.

49. CELAM, Conclusões de Medellín, op. cit., p. 146, énfasis nuestro.

50. G. Gutiérrez, "O Concílio Vaticano II na América Latina”, op. cit., pp. 48 y s.

51. Cf. A. M. Tepedino, "De Medellín a Aparecida, op. cit., pp. 376, 377 y 382, respectivamente.

52. A. Lorscheider, Mantenham as Lâmpadas acesas, op. cit., p. 77. Al hablar de la Conferencia de Santo Domingo, de la que dice que fue "más de los obispos, partiendo de Roma, que de los obispos latinoamericanos, partiendo de la realidad local", don Aloísio Lorscheider considera que "fue un fracaso" (ibid., p. 81). En la 
En Medellín se hizo realidad la insistencia/exigencia evangélica del cardenal Lercaro de colocar "como centro y alma del trabajo doctrinal y legislativo del concilio el misterio de Cristo en los pobres y la evangelización de los pobres". Y así, la Iglesia de Jesucristo aparece, de hecho, como ella es y como ella quiere y debe ser: la Iglesia de todos, pero, sobre todo, la Iglesia de los pobres.

\section{3. "Iglesia de los pobres": actualidad histórico-teologal}

A pesar de las reservas, las ponderaciones y los conflictos, en las décadas de los 70 y 80 la problemática de la "Iglesia de los pobres" o de la "opción preferencial por los pobres" se convirtió en el tema central en América Latina, para la comprensión tanto del misterio de la Iglesia como de su estructura y acción pastoral. En definitiva, si el ser "de los pobres" forma parte de la esencia de la Iglesia, eso debe traducirse y hacerse realidad en su estructura y acción pastoral ${ }^{53}$.

Todo ello repercutió, en forma e intensidad diferentes, en las iglesias de los otros continentes ${ }^{54}$ y hasta en el magisterio del obispo de Roma. Juan Pablo II, por ejemplo, lo afirmó varias veces en sus discursos y documentos ${ }^{55}$, particular-

medida en que estuvo más preocupada por "tener buenas relaciones diplomáticas con los Gobiernos" y más interesada en "defender a la Iglesia", dice que fue "un gran retroceso" (ibid., p. 82). Por no hablar del "desastre" teológico. "Yo me avergonzaba en Santo Domingo. Recuerdo que en el grupo en que yo estaba, el teólogo no sabía nada, y así eran los demás, era muy poca cosa. Fue una pena" (ibid., p. 83).

53. $C f$. I. Ellacuría, "Las bienaventuranzas, carta fundacional de la Iglesia de los pobres", en Escritos teológicos, t. II, op. cit., pp. 417-437; "El auténtico lugar social de la Iglesia", ibid., pp. 439-451; "La Iglesia de los pobres, sacramento histórico de liberación", ibid., pp. 453-485; "Notas teológicas sobre religiosidad popular", ibid., pp. 487-498; J. Sobrino, Ressurreição da verdadeira Igreja: Os pobres, lugar teológico da eclesiologia, São Paulo: Loyola, 1982; Á. Barreiro, Os pobres e o Reino: Do Evangelho a João Paulo II, São Paulo: Loyola, 1983; L. Boff, E a Igreja se fez povo. Eclesiogênese: A Igreja que nasce da fé do povo, Petrópolis: Vozes, 1991; J. Comblin, O Povo de Deus, São Paulo: Paulus, 2002, pp. 88-114; F. de Aquino Júnior, "Igreja dos pobres: sacramento do povo universal de Deus. Tópicos de uma eclesiologia macroecumênica da libertação", en L. Tomita, M. Barros y J. M. Vigil (coords.), Pluralismo e Libertação. Por uma Teologia Latino-americana Pluralista a partida Fé Cristã, São Paulo: Loyola, 2005, pp. 193-214.

54. Cf. E. Dussel, De Medellín a Puebla. Uma década de sangue e esperança, vol. III: Em torno de Puebla (1977-1979), São Paulo: Loyola, 1983, pp. 545-564; J. Comblin, "Puebla: veinte anos depois", Perspectiva Teológica 31 (1999), pp. 201-222, aquí p. 204.

55. Cf. Juan Pablo II, Carta Encíclica Solicitudo Rei Socialis, São Paulo: Paulinas, 1990, n. ${ }^{\circ}$ 42; Carta Encíclica Redemptoris Missio, São Paulo: Paulinas, 1990, n. ${ }^{\circ}$ 60; Carta Encíclica Centesimus Annus, São Paulo: Paulinas, 1991, n. ${ }^{\circ}$ 57; Carta Apostólica Novo Millennio Ineunte, São Paulo: Paulinas, 2001, n. 49. 
mente en sus primeros viajes a América Latina, donde habló, incluso, de la Iglesia como "Iglesia de los pobres" 56 . En su Carta Apostólica Novo millennio ineunte llega a afirmar que "si verdaderamente partimos de la contemplación de Cristo, debemos saber verlo sobre todo en el rostro de aquel con quien él mismo se quiso identificar". Refiriéndose a Mt 25, 35-36, dijo: "Esta página no es solo una invitación a la caridad, sino una página de cristología que proyecta un rayo de luz sobre el misterio de Cristo. Con esta página la Iglesia mide si pasa la prueba de la ortodoxia y su fidelidad de esposa de Cristo" ${ }^{\text {}}$. Así también el papa Benedicto XVI, siempre muy crítico de la Iglesia y de la teología de la liberación, reconoce y afirma explícitamente en el discurso inaugural de la Conferencia de Aparecida que la "opción preferencial por los pobres está implícita en la fe cristológica en el Dios que se hizo pobre por nosotros, para enriquecernos con su pobreza (cf. 2 Cor 8,9$)^{\prime \prime}{ }^{n}$.

Lo curioso y paradójico es que, en el momento en que se llega a cierto consenso - aunque formal o precisamente por eso- sobre la centralidad (¿preferencial?) de los pobres en la revelación y en la fe cristiana, esta va perdiendo relevancia y eficacia en la vida de la Iglesia. Es cierto que siempre es afirmado o admitido, o por lo menos no negado en principio, pero en la práctica es poco eficaz. Las palabras se admiten, se aceptan, pero no se toman en serio en las opciones y prioridades pastorales. Es lo que se puede constatar en la Iglesia latinoamericana a partir de la década de los noventa.

No sin razón, Clodovis Boff se refiere a la conferencia de Santo Domingo como a una especie de "ajuste pastoral" en la Iglesia de América Latina.

Como "ajuste pastoral" entendemos la reanudación del camino ya tradicional de la Iglesia latinoamericana, pero dándole otra dirección, una dirección no contraria, pero sí diferente a la establecida. En verdad, se trata de un redireccionamiento global. Los obispos retomaron el camino que viene de Medellín, pero en otro contexto y por eso con otra sensibilidad, con otra óptica. ${ }^{59}$

Para Boff, el "ajuste pastoral” realizado por Santo Domingo se da en un doble sentido.

56. Cf. Juan Pablo II, "Visita à Favela do Vidigal", en A Palavra de João Paulo II no Brasil: Discursos e homilias, São Paulo: Loyola, 1980, n. ${ }^{\circ}$ 4, 11, 14, 15, 19, $20,21$. Sobre el discurso de Juan Pablo II, cf. Á. Barreiro, Os pobres e o Reino, op. cit., pp. 146-154. El tema reaparece en su Carta Encíclica Redemptoris Missio, n. ${ }^{\circ} 60$.

57. Juan Pablo II, Carta Apostólica Novo Millennio Ineunte, op. cit., n. ${ }^{\circ} 49$.

58. Benedicto XVI, "Discurso inaugural", en CELAM, Documento de Aparecida, São Paulo: Paulinas/Paulus, 2007, pp. 249-266, aquí p. 255.

59. C. Boff, $O$ "Evangelho" de Santo Domingo: Os dez temas-eixo do Documento da IV CELAM, Petrópolis: Vozes, 1994, pp. 26 y s. 
Primero, ad intra, Santo Domingo refuerza la Iglesia-jerarquía, debilitando la Iglesia Pueblo de Dios. Segundo, ad extra, el IV CELAM privilegia la dimensión propiamente evangelizadora de la Iglesia, enfatiza su función específicamente religiosa y misionera [...], pero [...] no de modo que pretenda radicalizar la misión social de la Iglesia, sino que más bien la relativiza. ${ }^{60}$

Y aunque la conferencia de Aparecida haya avanzado bastante en relación a Santo Domingo, no fue capaz de retomar la dirección/orientación fundamental de Medellín y Puebla, sobre todo en lo que respecta a la centralidad de los pobres y oprimidos en la vida y misión de la Iglesia.

En todo caso, se trata aquí de una cuestión central y decisiva en la revelación y en la fe cristiana. Es por lo tanto innegociable desde el punto de vista teológico-pastoral. Y es extremamente relevante y urgente desde el punto de vista histórico-coyuntural. De ahí su actualidad histórico-teologal.

1. No hay que hacer gran esfuerzo para percibir que la miseria y la pobreza, con sus antiguas y nuevas expresiones, continúan siendo el drama, la urgencia y el desafío más grande de nuestro tiempo. Está en juego la vida de millones de personas a su nivel más básico y elemental: alimento, salud, vivienda...

Según el Informe sobre Desarrollo Humano 2010 del Programa de las Naciones Unidas para el Desarrollo (PNUD) ${ }^{61}$, a pesar de los avances logrados en las últimas décadas, el número absoluto de personas desnutridas en el mundo, que en 1980 era cerca de 850 millones, aumentó a cerca de mil millones de personas $^{62}$; cerca de un tercio de la población de 104 países, alrededor de 1.75 mil millones de personas, viven en pobreza multidimensional ${ }^{63}$; 1.44 mil millones viven con menos de 1.25 dólares al día y 2.6 mil millones viven con menos de 2 dólares al día ${ }^{64}$; el abismo entre países desarrollados y países en vías de desarrollo continúa aumentando: el país más rico actualmente (Liechtenstein) es tres veces más rico que el país más rico en 1970, y el país más pobre actualmente (Zimbabue) es aproximadamente 25 más pobre que el país más pobre de 1970

60. Ibid., p. 27. En la misma dirección va nuestro análisis de las últimas directrices pastorales de la CNBB ( $c f$. F. de Aquino Júnior, “'Novas' Diretrizes da Ação Evangelizadora: ‘Ajuste Pastoral'!?’, REB 284 (2011), pp. 926-931.

61. Cf. Programa das Nações Unidas para o Desenvolvimento, Relatório de Desenvolvimento humano 2010. A Verdadeira Riqueza nas Nações: Vias para o Desenvolvimento Humano. Disponible en: http://www.pnud.org.br/rdh. Accedido el 09/08/2012.

62. Cf. ibid., p. 38 .

63. $C f$. ibid., pp. 90, 100. Una familia puede ser considerada multidimensionalmente pobre si sufre privaciones en de 2 a 6 de los siguientes indicadores: nutrición, mortalidad infantil, años de escolaridad, hijos matriculados, combustible en la cocina, sanitarios, agua, electricidad, suelo y activos ( $c f$. ibidem).

64. Cf. ibid., p. 101. 
(también Zimbabue ${ }^{65}$; las tasas regionales de pobreza multidimensional varían entre cerca del $3 \%$ en Europa y Asia Central y 65\% en el África subsahariana; en América Latina y el Caribe, la pobreza multidimensional varía del $2 \%$ de la población (Uruguay) al 57\% (Haití, antes del terremoto de 2010) ${ }^{66}$.

En Brasil, los datos del Instituto de Investigación Económica Aplicada (IPEA, por sus siglas en portugués) revelan que, entre 1978 y 2008, aunque haya habido una reducción significativa de la pobreza absoluta (ingreso familiar per cápita de hasta medio salario mínimo), hubo por otro lado un aumento significativo de pobreza relativa (hasta el 60\% del ingreso medio de los ocupados con más de 15 horas semanales ${ }^{67}$. Mientras la pobreza absoluta bajó del $71.5 \%$ al $31.4 \%$, la pobreza relativa aumentó de $23.7 \%$ a $45.2 \%{ }^{68}$. Junto a la reducción de la pobreza absoluta, mayor en la región del sur (de $68.8 \%$ a $16.1 \%$ ) que en la región nordeste (de $88.0 \%$ a $47.2 \%)^{69}$, el aumento de la pobreza relativa fue mayor en la región del nordeste (de $8.8 \%$ a $37.2 \%$ ) que en la región del sureste (de $33.4 \%$ a $49.1 \%)^{70}$, lo que muestra una gran desigualdad regional permanente en el país. En cualquier caso, "la tendencia positiva de reducción de la pobreza absoluta parece implicar el movimiento hacia la pobreza relativa" ${ }^{11}$, es decir, aumento en la concentración $\mathrm{y}$ en la desigualdad social ${ }^{72}$.

2. Esta situación nos debería hacer más sensibles y estar más alertas a la dimensión "esencial y primordial" de la revelación y fe cristiana de la cual hablaba el cardenal Lercaro en la última semana de la primera sesión del concilio: el "misterio de Cristo en los pobres", y consecuentemente a la centralidad de los pobres en la vida y misión de la Iglesia.

65. Cf. ibid., p. 44.

66. Cf. ibid., p. 103.

67. El concepto pobreza absoluta indica la carencia o satisfacción del mínimo necesario para la subsistencia. El concepto pobreza relativa apunta al problema de desigualdad social, es decir, de la distribución de la riqueza producida.

68. Cf. M. Pochmann, "Pobreza em transformação no Brasil", en P. Ribeiro de Oliveira (coord.), Opção pelos pobres no século XXI, São Paulo: Paulinas, 2011, pp. 59-85, aquí pp. 69 y s.

69. Ibid., p. 63.

70. Ibid., p. 70.

71. Ibid., p. 72.

72. El atlas de exclusión social en Brasil muestra que en 2001 "los $10 \%$ más ricos de la población poseían cerca de $3 / 4$ partes de toda la riqueza nacional" (M. Pochmann et al. [coords], Atlas da Exclusão Social, vol. 3: Os ricos no Brasil, São Paulo: Cortez, 2004 , p. 27) y que las "5 mil familias 'muy ricas' del país" (el $0.001 \%$ de las familias) se apropiaban "del equivalente al $3 \%$ de la renta total nacional, y su patrimonio representa alrededor del $40 \%$ del PIB brasileño" (ibid., p. 29), es decir, " $2 / 5$ de todo el flujo de renta generado por el país en el período de un año” (ibid., p. 11). 
Los estudios bíblicos ${ }^{73}$ y cristológicos ${ }^{74}$ de las últimas décadas han mostrado de modo cada vez más unánime que no se puede hablar de Jesucristo si no es a partir de y en función del reinado de Dios, y que en el centro del reinado de Dios está la justicia a los pobres y oprimidos, esto es, la garantía y defensa de sus derechos. Joachim Jeremias, exegeta alemán, por ejemplo, afirma que "el tema central de la proclamación pública de Jesús fue el reinado de Dios"75 y que "su rasgo decisivo" consiste en la "oferta de salvación hecha por Jesús a los pobres" ${ }^{\prime 6}$. En este sentido, llega a afirmar de manera chocante, o escandalosa, que el reinado de Dios "pertenece únicamente a los pobres" 77 . Y Jacques Dupont, exegeta belga, afirma que en los Evangelios "los pobres son vistos como los beneficiarios privilegiados del Reino de Dios" 78 , y que ese privilegio "debe ser buscado no en un análisis gratuito de la psicología de los mismos pobres, sino

73. Cf. G. Bornkamm, Jesus de Nazaré, Petrópolis: Vozes, 1976, pp. 60-90; R. Schnackenburg, Reino y reinado de Dios. Estudio bíblico-teológico, Madrid: Faz, 1974; "Reino de Deus", en J. B. Bauer, Dicionário de teologia bíblica, vol. II, São Paulo: Loyola, 1988, pp. 947-964; J. Jeremias, Teologia do Novo Testamento, São Paulo: Hagnos, 2008, pp. 159-193; W. G. Kümmel, Síntese teológica do Novo Testamento, São Leopoldo: Sinodal, 1983, pp. 21-108; R. Fabris, Jesus de Nazaré: história e interpretação, São Paulo: Loyola, 1988, pp. 89-179; J. Mateos, A utopia de Jesus, São Paulo: Paulus, 1994; J. Gnilka, Jesus de Nazaré: mensagem e história, Petrópolis: Vozes, 2000, pp. 83-153; G. Vanoni y B. Heininger, Das Reich Gottes, Würzburg: Echter, 2002; X. Léon-Dufour, Agir segundo o Evangelho. Palavra de Deus, Petrópolis: Vozes, 2003, pp. 23-54; C. Petersen, Die Botschaft Jesu vom Reich Gottes. Aufruf zum Neubeginn, Stuttgart: Kreuz, 2005; B. J. Malina, O evangelho social de Jesus: o reino de Deus em perspectiva mediterrânea, São Paulo: Paulus, 2004.

74. Cf. W. Pannenberg, Theologie und Reich Gottes, Gütersloh: Gerd Mohn, 1971; L. Boff, Jesus Cristo Libertador, Petrópolis: Vozes, 1991, pp. 38-59; E. Schillebeeckx, Jesus: história de um vivente, São Paulo: Paulus, 2008, pp. 99-263; J. I. González Faus, Acesso a Jesus: ensaio de teologia narrativa, São Paulo, Loyola, 1981, pp. 34-46; W. Kasper, Der Gott Jesu Christi, Mainz: Grünwald, 1982, pp. 205-216; K. Rahner, Curso Fundamental da Fé, São Paulo: Paulus, 1989, pp. 297-302; H. Kessler, "Cristologia", en T. Schneider, Manual de Dogmática, I, Petrópolis: Vozes, 2002, pp. 219-400, aquí pp. 242-247; J. L. Segundo, A história perdida e recuperada de Jesus de Nazaré, São Paulo: Paulus, 1997, pp. 142-262; J. Sobrino, Jesus, o Libertador: a história de Jesus de Nazaré, Petrópolis: Vozes, 1996, pp. 103-201; J. Moltmann, O Caminho de Jesus Cristo, Petrópolis: Vozes, 1994, pp. 137-164; Quem é Jesus Cristo para nós hoje?, Petrópolis: Vozes, 1997, pp. 11-32; B. Ferraro, Cristologia, Petrópolis: Vozes, 2004, pp. 77-96; J. Ratzinger, Jesus de Nazaré, São Paulo: Planeta, 2007, pp. 57-70.

75. J. Jeremias, Teologia do Novo Testamento, op. cit., p. 160.

76. Ibid., p. 176.

77. Ibid., p. 187.

78. J. Dupont, "Os pobres e a pobreza segundo os ensinamentos do Evangelho e dos Atos dos Apóstolos", en J. Dupont, A. George et al., A pobreza evangélica, São Paulo: Paulinas, 1976, pp. 37-66, aquí p. 37. 
en el contenido de la buena-nueva que les es anunciada"79. La Buena Noticia del Reino de Dios solo puede ser comprendida en referencia al "ideal regio" del antiguo Oriente próximo, en el cual, "el rey, por su propia misión, es el defensor de aquellos que no son capaces de defenderse por sí mismos"; "él es el protector del pobre, de la viuda, del huérfano y del oprimido" ${ }^{80}$. En este sentido, dice Dupont, "se podrá comprender perfectamente que el anuncio del Adviento del Reino de Dios constituye una buena-nueva, precisamente para los pobres y los desgraciados. Ellos deben ser los beneficiarios del Reino"81.

Ahora bien, en la medida en que la Iglesia es la comunidad de los seguidores y seguidoras de Jesucristo, y en la medida en que en el centro de la vida y misión de Jesucristo está el reinado de Dios, cuya característica más central y decisiva es la garantía de los derechos de los pobres y oprimidos, la Iglesia se constituye en "Iglesia de los pobres", para usar la expresión del papa Juan XXIII. El ser "de los pobres" aparece, aquí, como un aspecto "esencial y primordial" del "misterio de Cristo en la Iglesia" (cardenal Lercaro) ${ }^{82}$, uno de los "trazos" esenciales de la Iglesia (Marie-Dominique Chenu) ${ }^{83}$, "una nota constitutiva y configurativa de toda la Iglesia" (Ignacio Ellacuría) ${ }^{84}$, una dimensión "esencial de la 'verdad' de la Iglesia" (Álvaro Barreiro) ${ }^{85}$. Se trata, por lo tanto, de una cuestión dogmática, de una verdad fundamental de la revelación y de la fe cristiana, de una cuestión de ortopraxis eclesial y de ortodoxia teológica ${ }^{86}$, sin la cual la "Iglesia" puede ser todo, menos Iglesia de Jesucristo. La Iglesia que es y debe ser cada vez más una, santa, católica y apostólica (Concilio de Constantinopla en 381) es y debe ser siempre más de los pobres (Juan XXIII). Esa nota es tan esencial y fundamental en la Iglesia como las otras. Y es tan antigua como ellas, aunque su formulación en términos dogmáticos sea reciente.

Ciertamente, el ser de los pobres no agota la realidad de la Iglesia. La Iglesia que es de los pobres es también y siempre una, santa, católica y apostólica, para usar la formulación niceno-constantinopolitana. Pero esa es una de sus notas constitutivas y esenciales. De modo que, sin ella, la Iglesia deja de ser Iglesia de Jesucristo - su cuerpo vivo y actuante en la historia-.

Justamente porque la "opción" preferencial por los pobres pertenece al corazón del Evangelio de Jesucristo, cuando un "cristiano" [o una comunidad]

79. Ibid., p. 51.

80. Ibid., p. 53.

81. Ibid., p. 54.

82. G. Lercaro, en P. Gauthier, O Concílio e a Igreja dos pobres, op. cit., p. 179.

83. M. D. Chenu, “A igreja dos pobres no Vaticano II", Concilium 124 (1977), pp. 61-66, aquí p. 61.

84. I. Ellacuría, "Pobres", op. cit., pp. 171-192, aquí p. 189.

85. Á. Barreiro, Os pobres e o Reino, op. cit., p. 154.

86. $C f$. F. de Aquino Júnior, "Igreja dos pobres", op. cit., p. 210. 
no asume conscientemente en su vida, procurando vivirla con mayor fidelidad, y más aún cuando de hecho se opone a ella, cualquiera que sean las razones aducidas, él [ella] deja ipso facto de ser cristiano, pues se coloca en contradicción frontal con el Evangelio del Reino proclamado por Jesús y con la misma persona de Jesús que es, en la expresión de Orígenes, la autobasileia, el Reino en persona. ${ }^{87}$

En qué consiste concretamente ese ser de los pobres o cómo este configura la Iglesia en su totalidad depende del contexto histórico, de las formas que van adquiriendo la pobreza y la opresión, así como de las posibilidades reales, de los esfuerzos y de las luchas por su superación. Estamos, por tanto, ante una verdadera fe que se verifica (se hace verdad) en la historia, adquiriendo así diferentes configuraciones y expresiones. Para abordar más amplia y consecuentemente la Iglesia de los pobres, es preciso considerar tanto su carácter teológico-dogmático como su carácter histórico. Basta insistir ahora en que la Iglesia de los pobres es una Iglesia en la cual los pobres están en el centro; una Iglesia que se hace a partir y en función de los pobres y que encuentra en ellos su principio de estructuración, organización y misión. Y eso marca y determina radicalmente a la Iglesia en su totalidad: "Cuando los pobres se convierten en el centro de la Iglesia, ellos dan dirección y sentido a todo lo que legítimamente [...] y necesariamente [...] constituye la realidad concreta de la Iglesia: su predicación y acción, sus estructuras administrativas, culturales, dogmáticas, teológicas, etc."88.

Para terminar, conviene que hagamos dos advertencias. La primera, que ese ser de los pobres de la Iglesia no es una cuestión de "opción" en el sentido de que se podría también no optar, sino una conditio sine qua non para que la Iglesia sea de hecho Iglesia de Jesucristo. En otras palabras, para ser de Jesucristo tiene que ser de los pobres. Y no podría ser de otra manera una vez que, como afirma san Romero de América, "entre los pobres quiso poner Cristo su cátedra de redención" 89 . Por esa razón, afirma en otra ocasión, que "una Iglesia que no se une a los pobres para denunciar, desde los pobres, las injusticias que con ellos se cometen, no es verdadera Iglesia de Jesucristo" 90 . La segunda, que "los pobres no son de modo alguno causa de 'reducción' de la realidad eclesial; por el contrario, son fuente de concretización cristiana de toda realidad eclesial"91. Es decir, aunque el ser de los pobres no agota la realidad eclesial, es una de sus notas características o dimensiones esenciales y, como tal, configura la realidad eclesial en su totalidad - hace que la Iglesia, que es de todos, sea, sobre todo y antes de todo, la Iglesia de los pobres-.

87. Á. Barreiro, Os pobres e o Reino, op. cit., pp. 8 y s.

88. J. Sobrino, Jesus, o Libertador, op. cit., p. 103.

89. Mons. Ó. A. Romero, Homilías, t. IV, San Salvador: UCA Editores, 2007, p. 110.

90. Ibid., p. 277.

91. J. Sobrino, Jesus, o Libertador, op. cit. 


\section{A modo de conclusión}

A partir de la intuición/provocación del papa Juan XXIII en su mensaje al mundo el 11 de septiembre de 1962, de su repercusión y de su desdoblamiento en el Concilio Vaticano II, en la Conferencia de Medellín y en la teología latinoamericana, hemos intentado mostrar desde un punto de vista teológico, en qué sentido la Iglesia de Jesucristo es la Iglesia de los pobres; que el ser de los pobres es un rasgo, una nota, una característica o una dimensión esencial y fundamental de la Iglesia sin la cual ella deja ipso facto de ser Iglesia de Jesucristo. Se trata, pues, de una cuestión dogmática, de una verdad de fe; pero una verdad que debe ser verificada en la historia, es decir, de una verdad que debe ser hecha, realizada, encarnada...

Y aquí aparece otro aspecto de la reflexión sobre la Iglesia de los pobres que no hemos desarrollado en este trabajo. No es suficiente afirmar el carácter teológico-dogmático del ser de los pobres de la Iglesia, es necesario ver cómo ello se hace efectivo y se configura en la realidad eclesial en su totalidad. Es necesario ver cómo esa verdad se encarna y se hace realidad en una situación bien real y concreta. Para ello, entre otras cosas, es necesario considerar en cada época y en cada contexto quiénes son los pobres reales, cómo es su situación de pobreza, qué o quién provoca esa situación, cuáles son las posibilidades reales de enfrentamiento y superación de esa situación, cuáles son las mediaciones a disposición; pero todo esto supera los límites y las pretensiones de este trabajo.

En cualquier caso, es conveniente insistir en la complementariedad e inseparabilidad de esos dos aspectos al abordar la problemática de la Iglesia de los pobres: su carácter teológico-dogmático y su carácter histórico. Lo primero nos sitúa al nivel de los fundamentos o de las razones teológicas. Lo segundo nos sitúa al nivel de su realización y configuración histórica. Sin lo primero, la Iglesia de los pobres carece de fundamento teológico y acaba perdiendo relevancia en la vida de la Iglesia. Sin lo segundo, la Iglesia de los pobres queda reducida a una teoría abstracta e ineficaz. Es necesario, pues, afirmar su carácter teológico-dogmático (lo que aquí hemos hecho) y confrontarse con el problema de su realización histórica en los diferentes contextos (tarea a ser realizada). De una forma o de otra, se trata de una cuestión vital y esencial de la Iglesia de Jesucristo, en cuanto Iglesia de los pobres.

\section{Anexo. "Pacto de las catacumbas"92}

Nosotros, obispos, reunidos en el Concilio Vaticano II, conscientes de las deficiencias de nuestra vida de pobreza según el Evangelio; motivados los unos por

92. El 16 de noviembre de 1965, cerca de 40 padres conciliares (no se conoce el número exacto), en una celebración eucarística en las catacumbas de Santa Domitila, asumieron el compromiso de una Iglesia pobre y servidora de los pobres, firmando el llamado "Pacto de las Catacumbas" ( $c f$. B. Kloppenburg [coord.], Concílio Vaticano II, vol. V, op. cit., pp. 526-528). 
los otros en una iniciativa en la que cada uno de nosotros ha evitado el sobresalir y la presunción; unidos a todos nuestros hermanos en el episcopado; contando, sobre todo, con la gracia y la fuerza de nuestro Señor Jesucristo, con la oración de los fieles y de los sacerdotes de nuestras respectivas diócesis; poniéndonos con el pensamiento y con la oración ante la Trinidad, ante la Iglesia de Cristo y ante los sacerdotes y los fieles de nuestras diócesis, con humildad y con conciencia de nuestra flaqueza, pero también con toda la determinación y toda la fuerza que Dios nos quiere dar como gracia suya, nos comprometemos a lo que sigue:

1. Procuraremos vivir según el modo ordinario de nuestra población en lo que toca a casa, comida, medios de locomoción, y a todo lo que de ahí se desprende. Mt 5, 3; 6, 33s; 8-20.

2. Renunciamos para siempre a la apariencia y la realidad de la riqueza, especialmente en el vestir (ricas vestimentas, colores llamativos) y en símbolos de metales preciosos (esos signos deben ser, ciertamente, evangélicos). Mc 6, 9; Mt 10, 9s; Hech 3, 6. Ni oro ni plata.

3. No poseeremos bienes muebles ni inmuebles, ni tendremos cuentas en el banco, etc., a nombre propio; $\mathrm{y}$, si es necesario poseer algo, pondremos todo a nombre de la diócesis, o de las obras sociales o caritativas. Mt 6, 19-21; Lc 12, 33s.

4. En cuanto sea posible confiaremos la gestión financiera y material de nuestras diócesis a una comisión de laicos competentes y conscientes de su papel apostólico, para ser menos administradores y más pastores y apóstoles. Mt 10, 8; Hech 6, 1-7.

5. Rechazamos que verbalmente o por escrito nos llamen con nombres y títulos que expresen grandeza y poder (Eminencia, Excelencia, Monseñor...). Preferimos que nos llamen con el nombre evangélico de Padre. Mt 20, 25-28; 23, 6-11; Jn 13, 12-15.

6. En nuestro comportamiento y relaciones sociales evitaremos todo lo que pueda parecer concesión de privilegios, primacía o incluso preferencia a los ricos y a los poderosos (por ejemplo, en banquetes ofrecidos o aceptados, en servicios religiosos). Lc 13, 12-14; 1 Cor 9, 14-19.

7. Igualmente evitaremos propiciar o adular la vanidad de quien quiera que sea, al recompensar o solicitar ayudas, o por cualquier otra razón. Invitaremos a nuestros fieles a que consideren sus dádivas como una participación normal en el culto, en el apostolado y en la acción social. Mt 6, 2-4; Lc 15, 9-13; 2 Cor 12, 4.

8. Daremos todo lo que sea necesario de nuestro tiempo, reflexión, corazón, medios, etc. al servicio apostólico y pastoral de las personas y de los grupos trabajadores y económicamente débiles y subdesarrollados, sin que eso perjudique a otras personas y grupos de la diócesis. Apoyaremos a los laicos, religiosos, diáconos o sacerdotes que el Señor llama a evangelizar a los pobres y 
trabajadores, compartiendo su vida y el trabajo. Lc 4, 18s; Mc 6, 4; Mt 11, 4s; Hech 18, 3s; 20, 33-35; 1 Cor 4, 12 y 9, 1-27.

9. Conscientes de las exigencias de la justicia y de la caridad, y de sus mutuas relaciones, procuraremos transformar las obras de beneficencia en obras sociales basadas en la caridad y en la justicia, que tengan en cuenta a todos y a todas, como un humilde servicio a los organismos públicos competentes. Mt 25, 31-46; Lc 13, 12-14 y 33s.

10. Haremos todo lo posible para que los responsables de nuestro gobierno y de nuestros servicios públicos decidan y pongan en práctica las leyes, estructuras e instituciones sociales que son necesarias para la justicia, la igualdad y el desarrollo armónico y total de todo el hombre y de todos los hombres, y, así, para el advenimiento de un orden social nuevo, digno de hijos de hombres y de hijos de Dios. Hech 2, 44s; 4, 32-35; 5, 4; 2 Cor 8 y 9; 1 Tim 5, 16.

11. Porque la colegialidad de los obispos encuentra su más plena realización evangélica en el servicio en común a las mayorías en miseria física, cultural y moral - dos tercios de la humanidad-, nos comprometemos:

a compartir, según nuestras posibilidades, en los proyectos urgentes de los episcopados de las naciones pobres;

a pedir juntos, al nivel de organismos internacionales, dando siempre testimonio del Evangelio, como lo hizo el papa Pablo VI en las Naciones Unidas, la adopción de estructuras económicas y culturales que no fabriquen naciones pobres en un mundo cada vez más rico, sino que permitan que las mayorías pobres salgan de su miseria.

12. Nos comprometemos a compartir nuestra vida, en caridad pastoral, con nuestros hermanos en Cristo, sacerdotes, religiosos y laicos, para que nuestro ministerio constituya un verdadero servicio. Así, nos esforzaremos para "revisar nuestra vida" con ellos;

buscaremos colaboradores para poder ser más animadores según el Espíritu que jefes según el mundo;

procuraremos hacernos lo más humanamente posible presentes, ser acogedores;

nos mostraremos abiertos a todos, sea cual fuere su religión. Mc 8, 34s; Hech 6, 1-7; 1 Tim 3, 8-10.

13. Cuando regresemos a nuestras diócesis daremos a conocer estas resoluciones a nuestros diocesanos, pidiéndoles que nos ayuden con su comprensión, su colaboración y sus oraciones.

Que Dios nos ayude a ser fieles. 